\title{
INFORMATION ANALYTICAL REVIEW. 18TH INTERNATIONAL SCIENTIFIC SEMINAR "MATHEMATICAL MODELS AND MODELING IN LASER-PLASMA PROCESSES AND ADVANCED SCIENTIFIC TECHNOLOGIES" (LPPM3-2019)
}

\author{
V.I. MAZHUKIN* \\ M.V. Keldysh Institute of Applied Mathematics of RAS \\ Moscow, Russia \\ *Corresponding author. E-mail: vim@ modhef.ru
}

DOI: $10.20948 /$ mathmontis-2019-46-13

Summary. The results of the Eighteenth International Scientific Seminar "Mathematical Models and Modeling in Laser-Plasma Processes \& Advanced Scientific Technologies" (LPPM3-2019), which was held from September 29 to October 5, 2019 in Montenegro (Petrovac), are briefly summarized by the program committee of the seminar.

\section{INTRODUCTION}

The 18th International Scientific Seminar "Mathematical Models and Modeling in LaserPlasma Processes \& Advanced Scientific Technologies" (LPPM3-2019) was held from September 29 to October 5, 2019 in the city of Petrovac (Montenegro).

Figure 1 shows a photograph of the participants of the LPPM3-2019 workshop on the opening day. The Seminar organizers: M.V. Keldysh Institute of Applied Mathematics of Russian Academy of Sciences, A.M. Prokhorov Institute of General Physics of the Russian Academy of Sciences, University of Montenegro (Podgorica), Forum of Professors and Researchers of Montenegro, Scientific journal "Mathematica Montisnigri".

The seminar in 2019 coincided with the 100th anniversary of the birth of an outstanding Soviet and Russian scientist, academician of the Academy of Sciences of the USSR and the Russian Academy of Sciences Alexander Andreevich Samarskii (Fig. 2). Academician A.A. Samarskii is the founder of the Soviet and Russian schools of mathematical modeling, the creator of the fundamental general theory of difference schemes, an outstanding teacher, who brought up more than one generation of famous scientists, an active organizer and a bright propagandist of science. Scientific activity of academician A.A. Samarskii is firmly connected with the M.V. Keldysh Institute of Applied Mathematics, Academy of Sciences of the USSR and the Russian Academy of Sciences and the Institute of Mathematical Modeling of the Russian Academy of Sciences, which he headed. A brilliant scientist and an excellent organizer, he laid the potential to preserve the world level of Russian science in the most important field of mathematical modeling for our country.

The 18th International Scientific Seminar LPPM3 celebrated the 10th anniversary of its holding in Montenegro. The seminar "Mathematical models and modeling in laser-plasma processes and advanced scientific technologies" (LPPM3) was founded in 2004. The first five years, the organizers of the Seminar were two institutes of the Russian Academy of Sciences:

2010 Mathematics Subject Classification: 00B20, 00A66, 97M10, 97M50.

Key words and Phrases: Proceedings of conferences of general interest, Mathematical Modeling, Computational Mathematics, Laser Technology, Parallel/Distributed Computing, Heterogeneous Computational Technologies, Russian Space, Advanced Science Technology. 
M.V. Keldysh Institute of Applied Mathematics and the A.M. Prokhorov Institute of General Physics. During this period, the scientific theme of the seminar was devoted to one direction "Mathematical Models and Modeling in Laser-Plasma Processes" and was constantly held in Moscow. In 2009, after joining of a group of researchers from the University of Montenegro, a new direction was formed, "Mathematical Modeling in Advanced Scientific Technologies," and the seminar site https://lppm3.ru appeared. Since that time, the seminar has been constantly held in Montenegro.

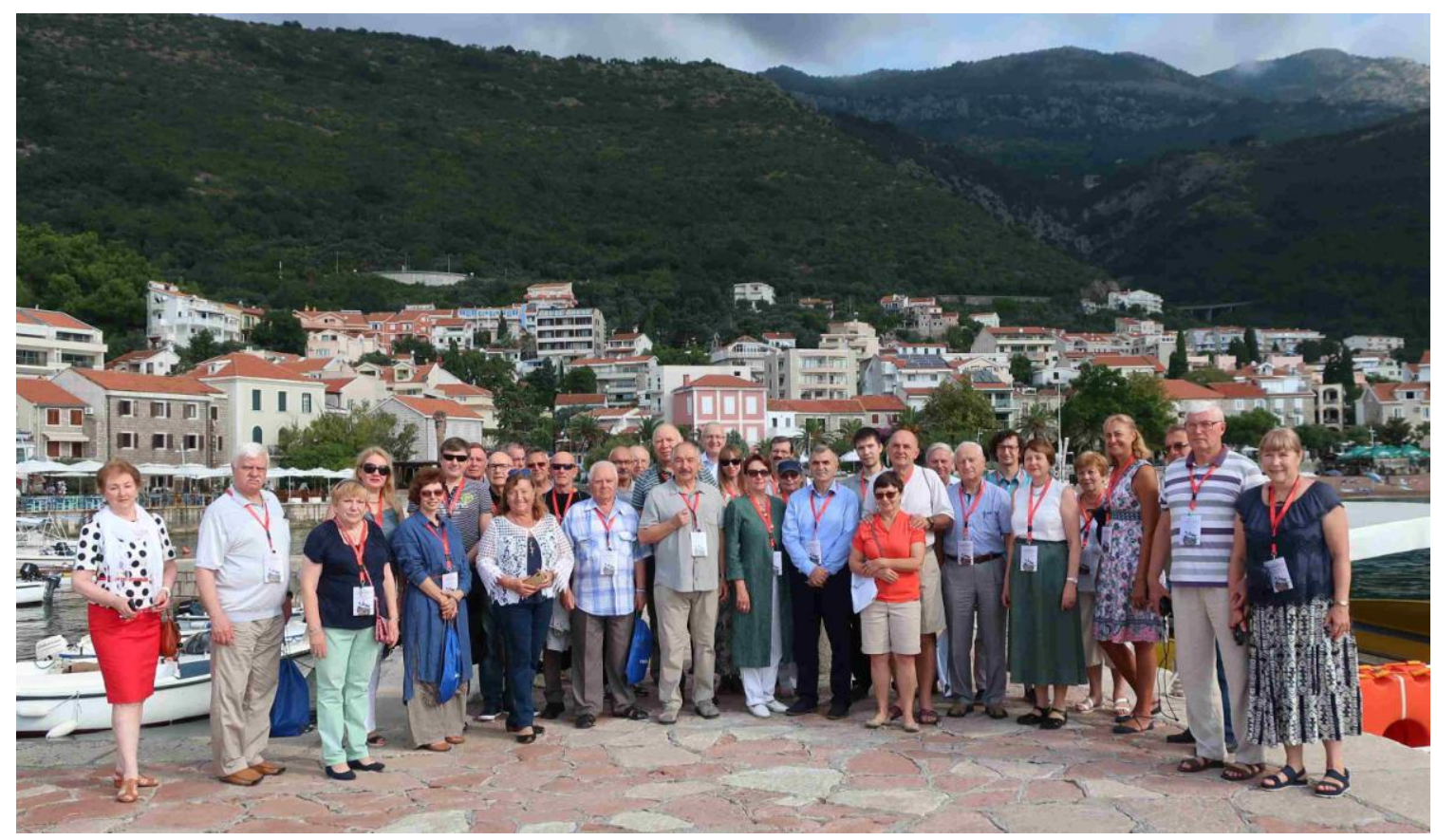

Fig. 1. The participants of the seminar LPPM3-2019 in the opening day.

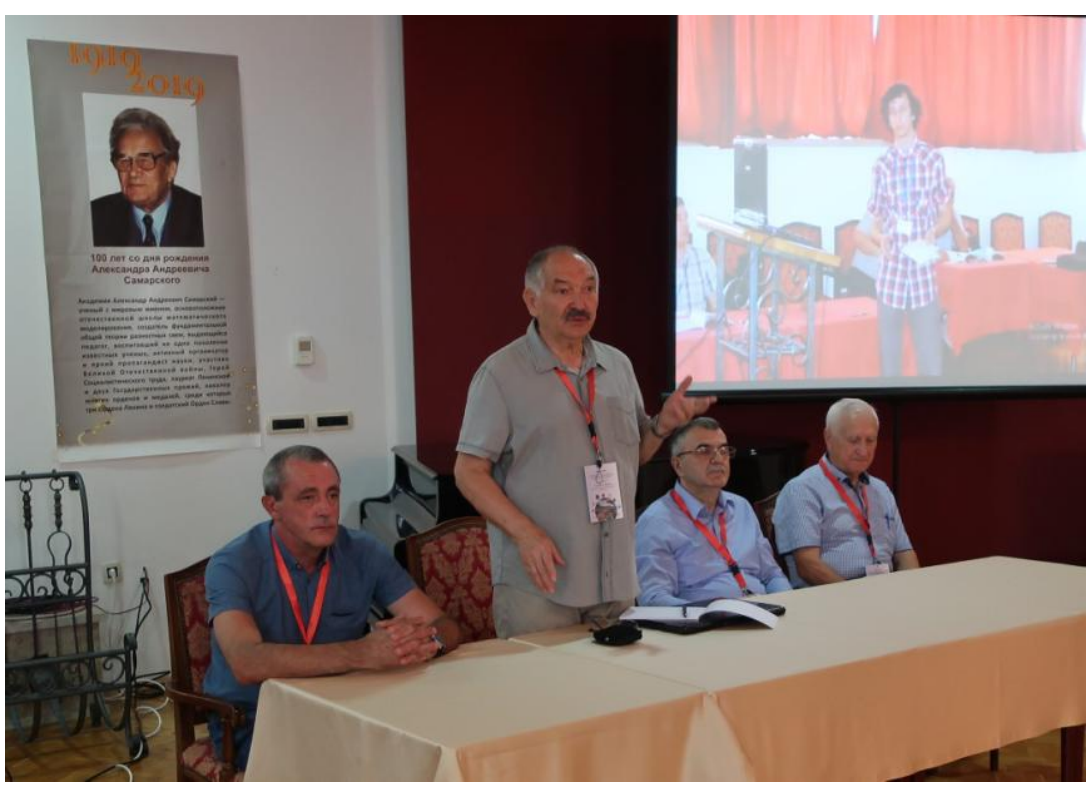

Fig. 2. The opening of the seminar LPPM3-2019 


\section{MAIN CHARACTERISTICS OF THE SEMINAR}

The representatives of more than 25 Russian and foreign scientific organizations attended the seminar in 2019. The composition of the 18th Seminar, scientific organizations and the number of participants is presented in the diagram (Fig. 3). The most numerous was the representation of the M.V. Keldysh Institute of Applied Mathematics of RAS (37\%). From Russia, the scientific results were presented by researchers of eight scientific centers and institutes of the Russian Academy of Sciences, 10 universities. Montenegro was represented by researchers at the University of Montenegro. The researchers from the University of Nova Gorica (Slovenia), the University of East Sarajevo (Bosnia and Herzegovina), the University of Bangor (Bangor, Gwynedd, United Kingdom), the University of Bielefeld (Munster, Germany), Friedrich Schiller University of Jena (Germany), A*STAR Research Center (Singapore) and the University of Rochester (USA) attended the 18th LPPM3 seminar.

By tradition, the Seminar is supported by the scientific journal Mathematica Montisnigri. The journal, as before, will publish articles on the most interesting reports of 2019. The publication on the pages of the journal of innovative articles with scientific novelty and tested at the Seminar contributes to the development of mathematical science, demonstrates to the scientific community the possibilities of the methodology of mathematical modeling.

In February 2019, the 100th anniversary of the birth of Alexander Andreevich Samarskii was celebrated. He was an outstanding Soviet and Russian scientist, academician of the USSR Academy of Sciences and the Russian Academy of Sciences. The interdisciplinary focus, based on the scientific methodology of mathematical modeling, which is traditional for the LPPM3 Workshop, is a continuation and development of the ideas of A.A. Samarskii. Prof. V.I. Mazhukin (M.V. Keldysh IAM of RAS, Russia), the chairman of the program committee of the seminar devoted the plenary report "Formation of mathematical modeling. To the 100th anniversary of academician A.A. Samarskii "[1] to the prospects for the development of the methodology of mathematical modeling, first formulated by Academician A.A. Samarskii. The methodology of mathematical modeling, which is the scientific platform of the LPPM3 seminar, allows one to bring together scientists working in various subject areas: mathematics, physics, chemistry, biology, medicine, economics, history.

In three plenary and six invited reports, the main scientific directions of the seminar were formulated. Among the plenary and invited reports, one of the main areas discussed was the problem of short-pulse (nanosecond) laser action on condensed matter, which is one of the most popular subject areas of mathematical modeling. The experimental aspects were considered in plenary reports [2,3]. The prospects for the use of laser action in medicine are the subject of a plenary report [2] presented by the A.M. Prokhorov GPI of RAS, Russia. The report discussed the results of studies of laser-plasma action as an effective tool used in surgery and therapy. The plenary report [3], which was also presented by the A.M. Prokhorov GPI of RAS, was devoted to the study of phenomena arising in liquid mercury under the influence of short laser pulses. The report presented experimental results that demonstrate the behavior of pressure pulses, which may be due to the metal-insulator transition in the nearcritical region of mercury. In the plenary report [4] presented by M.V. Lomonosov Moscow State University (Moscow, Russia), high-order Fano resonances and giant magnetic fields in dielectric microspheres are reported. Such resonators provide magnetic nanostructured generators with giant magnetic fields, which is attractive for many applications. 


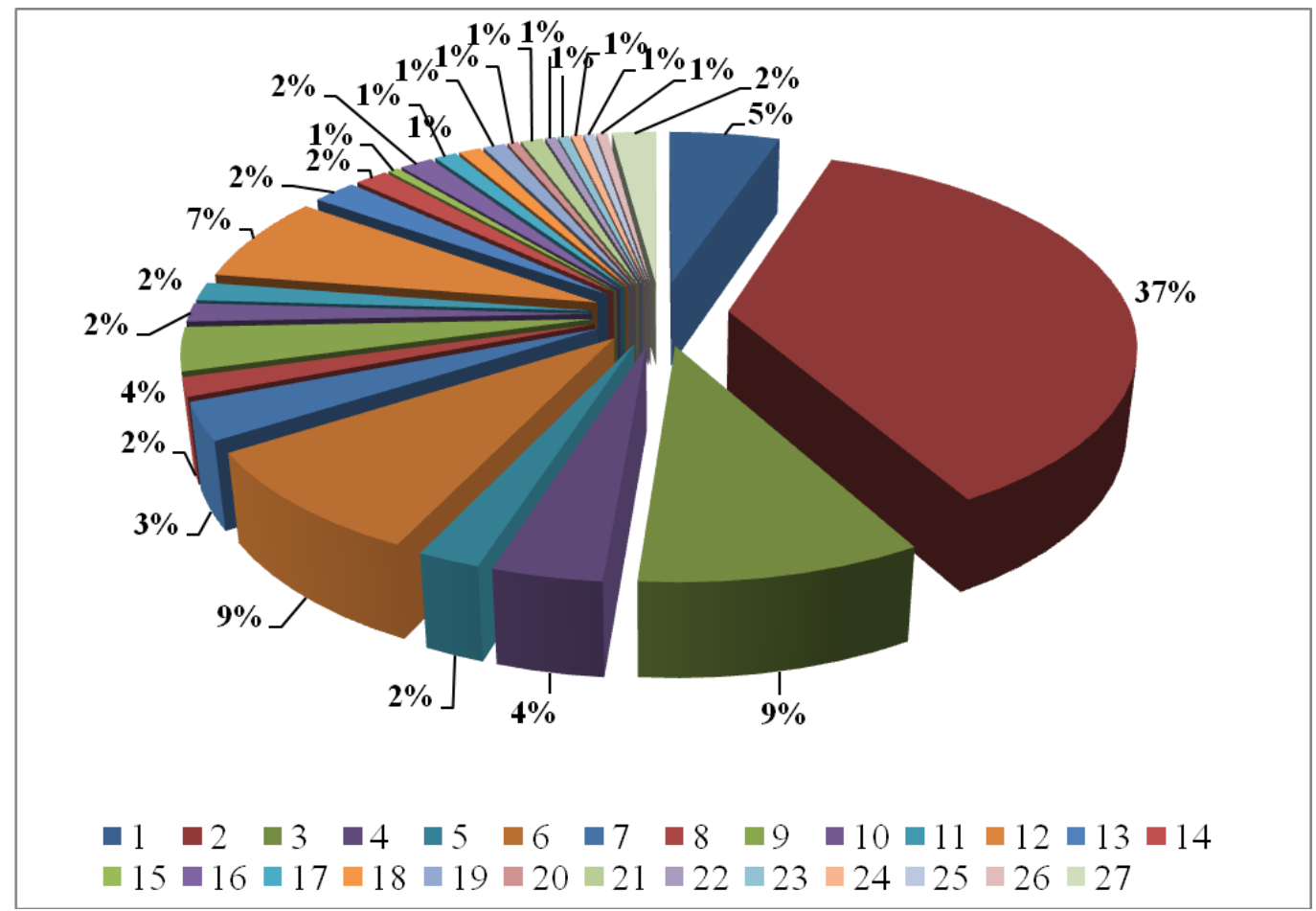

Fig. 3. The chart of the distribution of the number of speakers by scientific organizations. Designations on the diagram:

\section{National Research Nuclear University MEPhI,} Moscow, Russia

M.V. Keldysh Institute of Applied Mathematics of RAS, Moscow, Russia

A.M. Prokhorov GPI of RAS, Moscow, Russia

P. N. Lebedev Physical Institute of RAS, Moscow, 18 Russia

Space Research Institute of RAS, Moscow, Russia

$$
\text { ITMO University, Saint Petersburg, Russia }
$$

M.V. Lomonosov Moscow State University, Moscow, Russia

Scientific Research Institute for System Analysis of RAS, Moscow, Russia

M.A. Lavrentyev Institute of Hydrodynamics SB of RAS, Novosibirsk, Russia Joint Institute of High Temperature of RAS, Moscow, Russia

National University of Science and Technology «MISIS», Moscow, Russia

University of Montenegro, Podgorica, Montenegro University of East Sarajevo, Bosnia and Herzegovina

Novosibirsk State University, Novosibirsk, Russia
15 Friedrich Schiller University of Jena, Germany

16 Bauman Moscow State Technical University, Moscow, Russia Nova Gorica University, Slovenia University of Rochester, USA

19 Fiber Optics Research Center of RAS, Moscow, Russia

I.M. Gubkin Russian State University of Oil and Gas, Moscow, Russia

21 Ural Federal University, Yekaterinburg, Russia

Moscow Automobile And Road Construction State Technical University, Russia Bangor University, UK

\section{A*STAR Research, Singapore}

MIREA - Russian Technological University, Moscow, Russia

University of Bielefeld, Munster, Germany

School of Mathematics and Physics № 2007, Moscow, Russia 
The experimental aspects of the problem of laser action on condensed matter were also considered in invited papers [5, 6]. The report [5], presented by the researchers from ITMO (St. Petersburg, Russia), was devoted to the urgent problem of manufacturing new optical components using compressed laser-induced microplasma (SLIMP). A new method for the experimental study of the thermophysical properties of a wide range of conductive substances at a high level of pressure temperatures was reported in an invited report [6] presented by the Joint Institute of High Temperature of RAS (Moscow, Russia).

Based on the results of the theoretical studies, the main tool of which is mathematical modeling, an invited report is presented [7]. It presents the results of mathematical modeling of the collision process of two molecular clouds (MC) in a central collision. Collisions of the $\mathrm{MC}$ are one of the key mechanisms for the formation of new stars (Scientific Research Institute for System Analysis of RAS, M.V. Lomonosov Moscow State University, Moscow, Russia).

The topic "Models and Algorithms for High Performance Computing" was presented by the invited reports [8,9]. The report [8] presented an effective technology for mathematical modeling of the acceleration of solids and plasma under the influence of electromagnetic forces. For mathematical modeling, the Temetos software platform was developed, which allows one to specify spatial areas of complex geometric shape and build concentrating grids in them, including unstructured ones,. The platform contains a number of service modules for preparing, launching and analyzing the results of calculations on a supercomputer, including visualization of the resulting solution. Using the modules developed for the Temetos platform, physical fields were calculated for a number of configurations of magnetic accelerators, including rail-accelerated ones, and work was done on modeling plasma acceleration under astrophysical conditions and research. The results obtained are in demand in many fundamental and applied problems. The report is presented by M.V. Keldysh IAM of RAS (Moscow, Russia).

The invited paper [9] presented by M.A. Lavrentyev Institute of Hydrodynamics of SB of RAS and Novosibirsk State University, (Novosibirsk, Russia), was devoted to the accuracy of MUSCL-type schemes when calculating shock waves. The report deals with the development of a difference scheme using the MUSCL reconstruction of numerical flows. This scheme is of particular interest because it underlies a whole class of monotone central-difference schemes of increased accuracy, the implementation of which does not use the solution of the Riemann problem at the boundary of adjacent cells of a difference grid (in contrast to standard MUSCL schemes).

The problems outlined in the plenary and invited reports were discussed during the sessions of the sections. The diagram (Fig. 4) shows the distribution of reports among the scientific organizations which submitted these reports for discussion at section meetings. According to the number of scientific reports presented at the LPPM3 seminar in 2019, the leader is the M.V. Keldysh Institute of Applied Mathematics of RAS. The share of reports of this institute in the total number of reports is $35 \%$. In second place in the number of reports presented, the main topic of which is "Models of mathematical physics and complex analysis", is the University of Montenegro. The share of Montenegro reports in the total amount is $22 \%$. The consequence of the fact that more than half of all reports were submitted by mathematical institutes was a change in the thematic structure (Fig. 5). The most numerous in 2019 were topics "Models and algorithms for high-performance computing" (23\% of the total number of reports) and "Models of mathematical physics and complex analysis "( $22 \%)$. 
The following topics in the contribution are "Mathematical modeling and computational experiment in applied problems" (13\%) and" Russian space "(13\%), most of the reports on the later topics are also presented by M.V. Keldysh IAM of RAS.

In the reports of the subject "Mathematical modeling and computational experiment in applied problems", the methodology of molecular dynamics modeling (MDM) was discussed, and the increasing importance in the studies of the atomistic approach associated with the development of computational tools was noted.

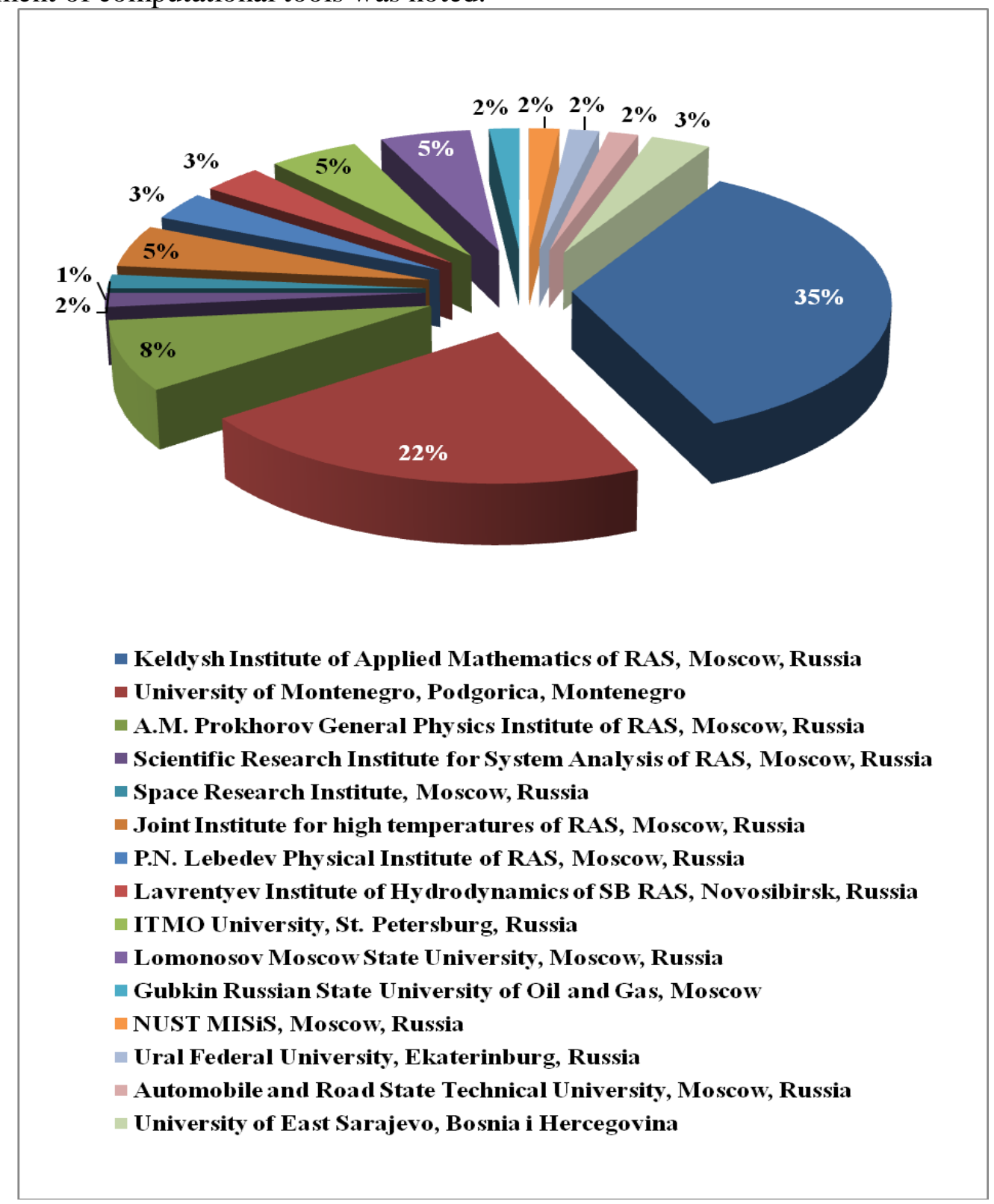

Fig. 4. Distribution chart of reports by scientific organizations of keynote speakers.

Within the framework of the molecular-dynamic methodology, the results of studies of the properties of metals [10] and semiconductors [11] in the field of melting and critical phenomena were presented (reports of M.V. Keldysh IAM of RAS). Within the topic, the 
M.V. Keldysh Institute of Applied Mathematics of RAS presented a number of reports on modeling of the radiation effects in various media [12-14]. The simulation results presented in the reports are used in the design of high-tech structural materials.

The traditional topic of the seminar "Russian space" icnluded $13 \%$ of all reports. The invited report [15] presents the results of an in-depth study of physics by schoolchildren on the example of school scientific work on measuring the thermal diameter of the Sun, carried out under the guidance of the community of collectives of the A.M. Prokhorov GPI of RAS and Physics and Mathematics School No. 2007 of Moscow (Russia).

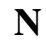

1

2

3

4

5

6

7

8

9

10

11

\section{Scientific topics of the seminar LPPM3}

Mathematical modeling and computational experiment in applied problems

Modeling of laser action on materials

Generation of nanoparticles and nanostructures

Continual and atomistic models

Laser ablation - experiment, theory, statements of the problems

Plasma theory and computational experiment

Models of mathematical physics and complex analysis

Models and algorithms for high performance computing

Russian space

Mathematical methods in biomedicine

Advanced scientific technology in the humanities

Table 1.

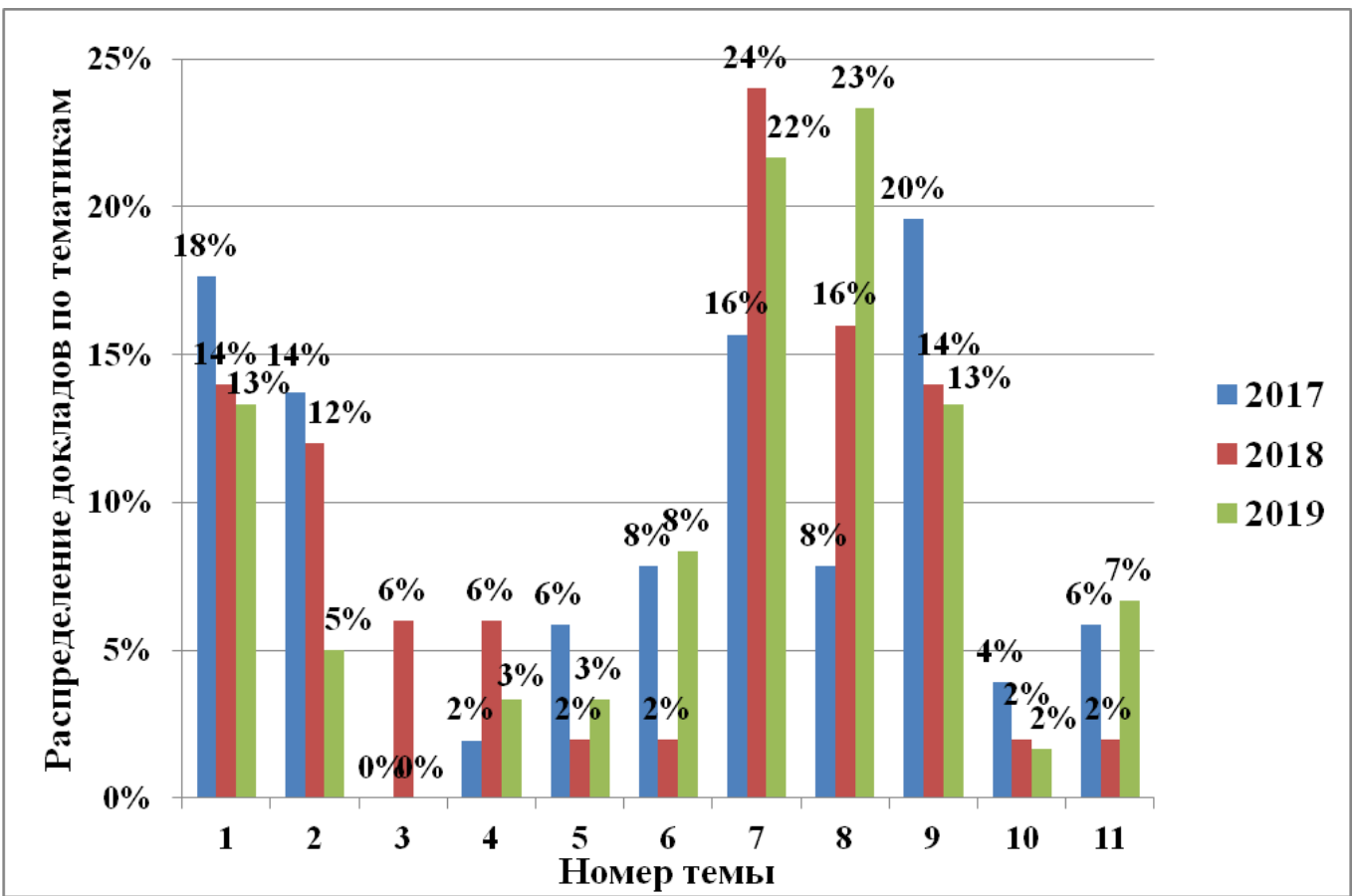

Fig. 5. Distribution of the reports over the scientific topics. The dynamics over the period from 2017 to 2019. The designations of scientific topics in the diagram are given in table 1. 
In the course of section discussions, the problems of observing space objects, the development of observing systems, and the statistical processing of the obtained data were considered [16-20]. The report [21] (Institute of Space Research of RAS, Moscow, Russia) presents the results of three-dimensional numerical simulation of heat propagation in the outer layers of magnetized neutron stars. Determining the structure of the magnetic field on the surface of a neutron star is an important task of modern astrophysics. In the report [22], presented by Scientific Research Institute for System Analysis of RAS (Moscow, Russia), the actual problem of modeling operator-controlled robots was considered. The methods and approaches of automatic control of a virtual anthropomorphic robot were discussed, with the help of which the operations of capturing, holding and moving objects of a virtual environment are implemented. The proposed methods and approaches are based on the use of virtual sensors, solving the inverse kinematics problem, and synthesizing force control.

Scientists of the University of Montenegro presented reports [23-33] in the areas of complex analysis (the results of studies of various spaces of analytical and harmonic functions are presented); algebra (the results of studies of various algebraic structures, such as hypernormal rings and semisimple n-dimensional bialgebras, are presented).

The materials of the participants of the conference LPPM3-2019 can be found on the website https://lppm3.ru/en/historyeng/history-of-programmes.

\section{DECISIONS OF THE SEMINAR}

The following decisions were made:

- to strengthen and develop international scientific cooperation in the field of the application of mathematical modeling in every way;

- to support the basic principles of the Seminar, strengthening its interdisciplinarity, attracting for this scientists from various fields of science;

- to hold in 2020 the 19th International Scientific Seminar LPPM3 in Montenegro.

The detailed information on the preparation of the seminar, presentation materials and results of annual sessions can be found on the website: http://lppm3.ru/.

The Chair of the Program Committee, Professor V.I. Mazhukin.

Acknowledgements: This work was supported by RFBR (project № 19-07-01001).

\section{REFERENCES}

[1] V.I. Mazhukin, "The genesis of mathematical modeling. To the 100th anniversary of academician A.A. Samarskii”, XVIII International Seminar Mathematical Model \& Modeling in Laser-Plasma Processes \& Advanced Science Technologies. Program and Abstracts. Petrovac, Montenegro, 48-49 (2019).

[2] D.G. Kochiev, I.A. Shcherbakov, S.V. Garnov, "Interaction of microsecond laser pulses with tissues: fundamentals and clinical applications", XVIII International Seminar Mathematical Model \& Modeling in Laser-Plasma Processes \& Advanced Science Technologies. Program and Abstracts. Petrovac, Montenegro, 50 (2019).

[3] A.A. Samokhin, E.V. Shashkov, N.S. Vorob'ev, A.E. Zubko, "Recoil pressure behavior during nanosecond laser pulse irradiation of mercury", XVIII International Seminar Mathematical Model \& Modeling in Laser-Plasma Processes \& Advanced Science Technologies. Program and Abstracts. Petrovac, Montenegro, 51-52 (2019). 
[4] B. Luk'yanchuk, Z. Wang, R. Paniagua-Domínguez, A. Bekirov, A.A. Fedyanin, "High order Fano resonances and giant magnetic fields in dielectric microspheres", XVIII International Seminar Mathematical Model \& Modeling in Laser-Plasma Processes \& Advanced Science Technologies. Program and Abstracts. Petrovac, Montenegro, 53 (2019).

[5] V.P Veiko, V.A. Shkuratova, G.K. Kostyuk, M.M. Sergeev, R.A. Zakoldaev, "Compressed laserinduced microplasma (CLIMP) and its application for fabrication of new optical components", XVIII International Seminar Mathematical Model \& Modeling in Laser-Plasma Processes \& Advanced Science Technologies. Program and Abstracts. Petrovac, Montenegro, 54-55 (2019).

[6] A.G. Kaptilny. "The study of the thermophysical properties of substances at high pressures and temperatures by the method of electrical explosion of conductors", XVIII International Seminar Mathematical Model \& Modeling in Laser-Plasma Processes \& Advanced Science Technologies. Program and Abstracts. Petrovac, Montenegro, 56-57 (2019).

[7] B.P. Rybakin, "Computer simulation of the formation of clumps formed by the collision of molecular clouds", XVIII International Seminar Mathematical Model \& Modeling in LaserPlasma Processes \& Advanced Science Technologies. Program and Abstracts. Petrovac, Montenegro, 60-61 (2019).

[8] M.P. Galanin, V.V. Lukin, A.S. Rodin, D.L. Sorokin, "Mathematical simulation of electromagnetic acceleration for solids and media with use of program platform Temetos", XVIII International Seminar Mathematical Model \& Modeling in Laser-Plasma Processes \& Advanced Science Technologies. Program and Abstracts. Petrovac, Montenegro, 64-67 (2019).

[9] O.A. Kovyrkina, V.V. Ostapenko. "On the accuracy of MUSCL type shock capturing schemes", XVIII International Seminar Mathematical Model \& Modeling in Laser-Plasma Processes \& Advanced Science Technologies. Program and Abstracts. Petrovac, Montenegro, 62-63 (2019).

[10] A.A. Aleksashkina, M.M. Demin, V.I. Mazhukin, "Determination of the phonon thermal conductivity of copper by molecular dynamics", XVIII International Seminar Mathematical Model \& Modeling in Laser-Plasma Processes \& Advanced Science Technologies. Program and Abstracts. Petrovac, Montenegro, 71-72 (2019).

[11] O.N. Koroleva, A.V. Mazhukin, M.M. Demin, P.V. Breslavskii, "Simulation of heat capacity and thermal conductivity of $\mathrm{Si}$ in a wide temperature range", XVIII International Seminar Mathematical Model \& Modeling in Laser-Plasma Processes \& Advanced Science Technologies. Program and Abstracts. Petrovac, Montenegro, 73-74 (2019).

[12] F.N. Voronin, V.A. Egorova, E.B. Savenkov, M.E. Zhukovskiy, "The modeling of radiationinduced thermomechanical effects in the finely dispersed medium", XVIII International Seminar Mathematical Model \& Modeling in Laser-Plasma Processes \& Advanced Science Technologies. Program and Abstracts. Petrovac, Montenegro, 112-113 (2019)

[13] S.V. Podolyako, S.A. Kazymov, M.B. Markov, S.V. Parotkin, I.A. Tarakanov, "On an algorithm of the simulating the proton transport considering the nuclear scattering", XVIII International Seminar Mathematical Model \& Modeling in Laser-Plasma Processes \& Advanced Science Technologies. Program and Abstracts. Petrovac, Montenegro, 114-115 (2019)

[14] V.A. Egorova, M.V. Alekseev, I.A. Tarakanov, R.V. Uskov, "The modeling of radiation-induced charge effects in the finely dispersed medium", XVIII International Seminar Mathematical Model \& Modeling in Laser-Plasma Processes \& Advanced Science Technologies. Program and Abstracts. Petrovac, Montenegro, 120 (2019)

[15] O.G. Tsarkova, S.N. Andreev, V.V. Belkov, P.S. Vasileva, N.E. Kondratyev, D.K. Kushnarev, "Thermal diameter of the Sun", XVIII International Seminar Mathematical Model \& Modeling in Laser-Plasma Processes \& Advanced Science Technologies. Program and Abstracts. Petrovac, Montenegro, 58-59 (2019)

[16] G.K. Borovin, A.V. Grushevskii, A.G. Tuchin, D.A. Tuchin, "Russian exploration of Venus: past and prospects", XVIII International Seminar Mathematical Model \& Modeling in Laser-Plasma 
Processes \& Advanced Science Technologies. Program and Abstracts. Petrovac, Montenegro, 81-82 (2019)

[17] E.A. Pavlova, "The Features and Management system of the space industry in the Russian Federation", XVIII International Seminar Mathematical Model \& Modeling in Laser-Plasma Processes \& Advanced Science Technologies. Program and Abstracts. Petrovac, Montenegro, 83 (2019)

[18] G.K. Borovin, Yu. F. Golubev, G. S. Zaslavsky, V. A. Stepanyants, A. G. Tuchin, “E.L. Akim's huge contribution to the Russian space research", XVIII International Seminar Mathematical Model \& Modeling in Laser-Plasma Processes \& Advanced Science Technologies. Program and Abstracts. Petrovac, Montenegro, 84-85 (2019)

[19] V.A. Voropaev, G.K. Borovin, E.A. Pavlova, A.I. Streltcov, M.V. Zakhvatkin, "The safety of high-orbit satellite spaceflights", XVIII International Seminar Mathematical Model \& Modeling in Laser-Plasma Processes \& Advanced Science Technologies. Program and Abstracts. Petrovac, Montenegro, 86 (2019)

[20] G.K. Borovin, Yu. F. Golubev, A.V. Grushevskii, A. G. Tuchin, "Formation of the main methods of the scientific school of V.V. Beletsky studying the rotational motions of artificial satellites and natural celestial bodies", XVIII International Seminar Mathematical Model \& Modeling in LaserPlasma Processes \& Advanced Science Technologies. Program and Abstracts. Petrovac, Montenegro, 87-88 (2019)

[21] S.G. Moiseenko, I.A.Kondratiev, G.S.Bisnovatyi-Kogan, M.V.Glushikhina, "3D numerical study of an anisotropic heat transfer in outer layers of magnetized neutron stars", XVIII International Seminar Mathematical Model \& Modeling in Laser-Plasma Processes \& Advanced Science Technologies. Program and Abstracts. Petrovac, Montenegro, 79-80 (2019)

[22] M.V. Mikhaylyuk, E.V. Strashnov, "Methods for space anthropomorphic robot control in virtual environment systems", ", XVIII International Seminar Mathematical Model \& Modeling in Laser-Plasma Processes \& Advanced Science Technologies. Program and Abstracts. Petrovac, Montenegro, 77-78 (2019)

[23] Ž. Pavićević, "Hyperbolic variations chord in the points Fatou of the bounded holomorphic functions", XVIII International Seminar Mathematical Model \& Modeling in Laser-Plasma Processes \& Advanced Science Technologies. Program and Abstracts. Petrovac, Montenegro, 106-107 (2019)

[24] Dušan Jokanović, "Relation between McCoy and Armendariz rings", XVIII International Seminar Mathematical Model \& Modeling in Laser-Plasma Processes \& Advanced Science Technologies. Program and Abstracts. Petrovac, Montenegro, 121 (2019)

[25] B. Zekovich, V.A. Artamonov, "Antipode in n - ary bialgebra", XVIII International Seminar Mathematical Model \& Modeling in Laser-Plasma Processes \& Advanced Science Technologies. Program and Abstracts. Petrovac, Montenegro, 122 (2019)

[26] Romeo Meštrović, Žarko Pavićević, "On some topological properties of Privalov spaces on the unit disk", XVIII International Seminar Mathematical Model \& Modeling in Laser-Plasma Processes \& Advanced Science Technologies. Program and Abstracts. Petrovac, Montenegro, 123 (2019)

[27] Kankaraš Milica, Irina Cristea, "Fuzzy reducibility in hypergroups", XVIII International Seminar Mathematical Model \& Modeling in Laser-Plasma Processes \& Advanced Science Technologies. Program and Abstracts. Petrovac, Montenegro, 124 (2019)

[28] Sanja Jancic Rasovic, Irina Cristea, Jelena Dakic, "An overview on the theory of hypernearrings", XVIII International Seminar Mathematical Model \& Modeling in Laser-Plasma Processes \& Advanced Science Technologies. Program and Abstracts. Petrovac, Montenegro, 125 (2019)

[29] Nikola Konatar, "Behavior of the interface between two immiscible fluids in the threedimensional case", XVIII International Seminar Mathematical Model \& Modeling in Laser- 
Plasma Processes \& Advanced Science Technologies. Program and Abstracts. Petrovac, Montenegro, 126 (2019)

[30] Marijan Markovic, "Characterisation of smooth functions with given growth", XVIII International Seminar Mathematical Model \& Modeling in Laser-Plasma Processes \& Advanced Science Technologies. Program and Abstracts. Petrovac, Montenegro, 128 (2019)

[31] Dakić Jelena Momir, "An overview of known hyper-power methods for computing of outer inverses and a new general Newton method", XVIII International Seminar Mathematical Model \& Modeling in Laser-Plasma Processes \& Advanced Science Technologies. Program and Abstracts. Petrovac, Montenegro, 130 (2019)

[32] Jela Šušić, "Extreme points of multidimensional functions", XVIII International Seminar Mathematical Model \& Modeling in Laser-Plasma Processes \& Advanced Science Technologies. Program and Abstracts. Petrovac, Montenegro, 143 (2019)

[33] Milenko T. Pikula, Dragana D. Nedić, Milica Č. Bošković, "Solution of the inverse boundary problem for the Sturm-Liouville operator with delay", XVIII International Seminar Mathematical Model \& Modeling in Laser-Plasma Processes \& Advanced Science Technologies. Program and Abstracts. Petrovac, Montenegro, 145 (2019)

Received October 25, 2019 